ORIENTAL JOURNAL OF CHEMISTRY

An International Open Access, Peer Reviewed Research Journal

www.orientjchem.org
ISSN: 0970-020 X

CODEN: OJCHEG

2019, Vol. 35, No.(6):

Pg. 1756-1759

Brief communication

\title{
Antimicrobial and Anti-inflammatory properties of Juglans regia Leaves
}

\section{ASMA ESWAYAH ${ }^{1 *}$, NAHLA LABYAD ${ }^{2}$, FADILAH ALEANIZY ${ }^{3}$, AMAL BELAID1, $^{1}$ FULWAH ALQAHTANI ${ }^{3}$ and HAYA ALFASSAM ${ }^{4}$}

\author{
${ }^{1}$ Department of Medicinal and Pharmaceutical Chemistry, Faculty of Pharmacy, \\ University of Tripoli, Tripoli, Libya. \\ ${ }^{2}$ Pharmacognosy Department, Faculty of Pharmacy, University of Tripoli, \\ Tripoli, Libya. \\ ${ }^{3}$ Department of Pharmaceutics, College of Pharmacy, King Saud University, Riyadh, Saudi Arabia. \\ ${ }^{4}$ King Abdulaziz City for Science and Technology, Riyadh, Saudi Arabia. \\ *Corresponding author E-mail: aeswayah@yahoo.com
}

http://dx.doi.org/10.13005/ojc/350618

(Received: July 10, 2019; Accepted: November 02, 2019)

\begin{abstract}
Antibacterial and Anti-inflammatory activities of methanolic extract of Juglans regia L. leaves (Walnut) grown in Libya were investiagted. Hot extraction method by methanol using Soxhlet apparatus was utilized.The antimicrobial effect was studied using agar diffusion method. Human red blood cell membrane stabilization (HRBC) method was used to estimate the anti-inflammatory properties of the leave extract. The extract of leaves exhibited antimicrobial activity against Staphylococcus aureus, and Candida albicans with a minimum inhibitory concentration (MIC) of 25 and $50 \mathrm{mg} / \mathrm{ml}$, respectively. In addition, the extract concentrations of 20,40 , and $100 \mu \mathrm{g} / \mathrm{mL}$ inhibited lysis of HRBC with values of $25.8 \%, 35.5 \%$, and $70 \%$, respectively. The results showed that the methanolic extract of Juglans regia leaves exhibited antibacterial activity against $S$. aureus, and antifungal activity against C. albican, and produced anti-inflammatory activity.
\end{abstract}

Keywords: Juglans regia leaves, Methanolic extract, Antimicrobial activity, Anti-inflammatory activity

\section{INTRODUCTION}

Herbal medicine was and still one of the leading contributions in the treatment of different disease. Many plants were considered as important element in traditional medicine. Last decades, the scientific attention increased to investigate plants for their active components ${ }^{1,2}$. An example of one of the valuable and medicinally useful herbs is
Juglans regia L, which belonged to Juglandaceae family. It's usually known as walnut, which is a large tree distributed throughout the world. The J. regia root, stem bark, leaves, seeds and cotyledons are used to treat a variety of health problems. Bactericidal properties of the Juglans were reported previously for different part of the plant $3,4,5$. The bark, leaf, seeds and green husks of Juglans regia are used as natural treatments in folk medicine. The bark and

This is an Open Access article licensed under a Creative Commons license: Attribution 4.0 International (CC- BY). Published by Oriental Scientific Publishing Company @ 2018

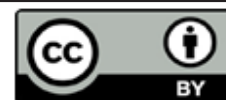


green husks have been analyzed for its antimicrobial, antifungal and anthelmintic activity; which attributed to diverse chemical constituents ${ }^{1,6,7}$. The plant leaves from Iranian regions were characterized for different activities ${ }^{8}$. The plant extract of leaves showed significant hypoglycemic action in both short and long term using leave extract ${ }^{9}$. Also, it was found that leaves showed good oral antimicrobial activity in patient suffering from dental carries ${ }^{4}$. A wide range of antibacterial medicines is used to treat these infections. But with the rise of multidrug resistance and the adverse effect accompanied some antibiotics it is preferable to have alternative therapy of herbal origin to minimize the multidrug resistance ${ }^{4}$. The endogensis and exogenesis factors, effect the plant chemical composition. Studies have reported that chemical compounds found in J.regia are different in different climate. The leaves of this plant rich with flavonoids, phenolic acids, essential fatty acids, ascorbic acid, caffeic acid, paracomaric acid and tannins, in addition to important flavonoids as quercetin galactoside and quercetin pantocid derivatives, quercetin arabinoside, quercetin xyloside, and quercetin rhamnoside ${ }^{10,11}$. In the current study, the methanolic extract of Libyan cultivated J.regia leaves was conducted and investigated for their antimicrobial and anti-inflammatory activities.

\section{MATERIALS AND METHODS}

\section{Collection of the leaves}

The plant sample of green leaves of Walnut (Juglans regia L.) was collected from local area in Tripoli in summer 2017 and authenticated by Taxonomy center of botany division and referenced (voucher specimen number 5971965). The green leaves were air dried in shade at room temperature to produce powder after grinding.

\section{Preparation of leaves extract}

A Soxhlet extraction method was performed according to the standard method described in literature. The powdered dried green leaves of the plant $(50 \mathrm{~g})$ placed inside a paper timber where the plant material was macerated at room temperature overnight in $250 \mathrm{ml}$ of methanol. Then the plant material was submitted to Soxhlet extraction for $8 \mathrm{~h}$ at a maximum temperature of $60^{\circ} \mathrm{C}$. The crude extracts were evaporated to obtain the dry extract and the extractive value was calculated.
Extractive value (24.4\%) determines the amount of active constituents in a given amount of medicinal plant material when extracted with a solvent.

\section{Antimicrobial activity Microorganisms}

The antimicrobial effect of methanolic extract obtained from Walnut was tested against four Gram-negative bacteria (Escherichia coli (ATCC 25922), Pseudomonas aeruginosa (ATCC 27853), Salmonella enterica (ATCC 25566), and Klebsiella pneumoniae (ATCC13883)) and two Gram-positive bacteria (Staphylococcus aureus (ATCC 25923), Bacillus subtilis) and Candida albicans fungi. The bacteria were initially reactivated from stock cultures, and maintained on Mueller Hinton broth (MHB) at $37^{\circ} \mathrm{C}$ for 18 hours.

\section{Agar diffusion method}

The antimicrobial properties of methanolic extract used in this study were determined according to the Clinical and Laboratory Standards Institute protocol utilizing agar well diffusion method with some modifications ${ }^{12}$. The bacteria were cultured on Mueller-Hinton Agar (MHA) at $37^{\circ} \mathrm{C}$ for 18 hours. MHA agar plates were inoculated with tested microrganisms at $0.5 \mathrm{McF}$ arland scale, and wells were filled with $50 \mu \mathrm{l}$ of Walnut methanolic extract in concentration ranging from 100 to $12.5 \mathrm{mg} /$ $\mathrm{mL}$ and incubated for $24 \mathrm{~h}$ at $37^{\circ} \mathrm{C}$, then diameter of inhibition zone was measured. Ciprofloxacin and Fluconazole $(1 \mu \mathrm{g} / \mathrm{mL})$ were utilized as positive control. The experiments were performed in triplicate and the zone of inhibition was recorded.

\section{Anti-inflammatory activity}

The in vitro anti-inflammatory activity of methanolic extract was screened as described previously ${ }^{5}$. Mixing freshly drawn human blood in an equal volume of sterilized Alsever's solution, followed by centrifugation at $3000 \mathrm{rpm}$ for $10 \mathrm{~min}$, and reconstiuted using normal saline at $10 \%(\mathrm{v} / \mathrm{v})$ was a first step. Then $1 \mathrm{~mL}$ of tested samples were prepared in normal saline at different concentrations $(20,40,60,80,100) \mu \mathrm{g} / \mathrm{mL}$ mixed with $1 \mathrm{~mL}$ of $0.2 \mathrm{M}$ phosphate buffer, $1 \mathrm{~mL}$ hypo saline, and $0.5 \mathrm{~mL}$ of $10 \%$ blood suspension, and subsequently incubated at $37^{\circ} \mathrm{C}$ for $30 \mathrm{~min}$, then centrifuged for $30 \mathrm{~min}$ at $3000 \mathrm{rpm}$. The haemoglobin content in the supernatant 
was determined using spectrophotometry at $560 \mathrm{~nm}$. Distilled water and diclofenac sodium were utiliized as control and standard, respectivelly, in which control representing no stability or $100 \%$ lysis, the percentage of inhibition of HRBC haemolysis determined by formula.

$\%$ Inhibition of Haemolysis = (O. D. of Control- O. D. of Test sample/O. D. of Control) X 100

Where O. D. represents the optical density or absorbance.

\section{RESULTS AND DISCUSSION}

\section{Antimicrobial activity}

J.regia exhibited many biological activities owing to their secondary metabolites such as phenolic and flavonoids, however, thier effect are variabe due to the influence of environmental factors ${ }^{5,13}$ and geographical region. Previous studies reported that the Walnut plant has antimicrobial activities against different microorganisms $\mathrm{s}^{4,7}$.

In the current study, the leave extract showed antimicrobial activity against Staphylococcus aureus, and Candida albicans where as; there was no effect on other microbial species (Fig. 1). Generally the extract exhibited a stronger antimicrobial activity and minimal inhibitory concentration (MIC) against Staphylococcus aureus $(25 \mathrm{mg} / \mathrm{mL})$ than Candida albicans (50 mg/mL) (Table1).

(A)
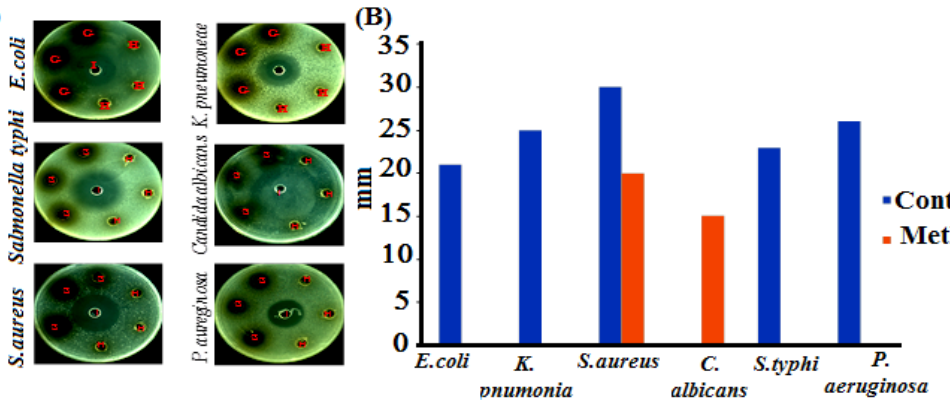

Fig. 1. Antimicrobial activity of Walnut Methanolic extract. (A) agar diffusion method was performed to examine antimicrobial activity of $100 \mathrm{mg} / \mathrm{mL}(\mathrm{G})$ and $1 \mathrm{mg} / \mathrm{mL}$ (H) of Wallnut methanolic extract against Escherichia coli, Klebsiella, Salmonella typhi, Candida albicans, Staphylococcus aureus, Pseudomonas aeruginosa, and antimicrobial agents (Ciprofloxacin and

Fluconazole) were used as positive control with the concentration of $1 \mu \mathrm{g} / \mathrm{ImL}$. (B) Zone of inhibition measurement

Table 1: Minimum inhibition concentration of Walnut methanolic extract

\begin{tabular}{lcccc}
\hline \multicolumn{4}{c}{ Concentrations of methanolic extract } \\
\hline Microorganism & $100 \mathrm{mg} / \mathrm{mL}$ & $50 \mathrm{mg} / \mathrm{mL}$ & $25 \mathrm{mg} / \mathrm{mL}$ & $12.5 \mathrm{mg} / \mathrm{mL}$ \\
Staphylococcus aureus & $18.33 \mathrm{~mm}$ & $14.33 \mathrm{~mm}$ & $10 \mathrm{~mm}$ & - \\
Candida albicans & $15 \mathrm{~mm}$ & $10.33 \mathrm{~mm}$ & - & - \\
\hline
\end{tabular}

The above results are consistent with some of previous studies in which the leave extract showed antimicrobial properties against Gram-positive not Gram-negative bacteria as they were resistant to leaves extract. In contrast, previous study found that Candida albicans was resistant to Juglans regia leaves extract? Moreover, another study reported that alkaloid of methanolic fraction of extract of Juglans regia produced moderated inhibition of Candida albicans growth ${ }^{5}$.

\section{Anti-inflammatory activity}

As presented in Table 2, the results demonstrated protection of the cell membrane in concentration-dependent pattern. The levels of protection of of Walnut methanolic extract observed were $25.8 \%, 35.5 \%$, and $70 \%$ for 20,40 , and $100 \mu \mathrm{g} /$ $\mathrm{mL}$ concentrations, respectively (Fig. 1). While the membrane stabilization of diclofenac sodium, were $36.6 \%, 42.6 \%$, and $85 \%$ at concentrations of 20 , 40, and $100 \mu \mathrm{g} / \mathrm{mL}$, respectively.

Table 2: Anti-inflammatory activity of Walnut methanolic extract

\begin{tabular}{ccc}
\hline $\begin{array}{c}\text { Concentration } \\
\mu \mathrm{g} / \mathrm{mL}\end{array}$ & $\begin{array}{c}\text { \%Hemolysis of } \\
\text { Methanolic } \\
\text { extract(\% } \pm \text { SD) }\end{array}$ & $\begin{array}{c}\text { \%Hemolysis of } \\
\text { Diclofenac } \\
\text { sodium(\% } \pm \text { SD) }\end{array}$ \\
\hline 20 & $25.8 \pm 0.06$ & $36.6 \pm 0.006$ \\
40 & $35.5 \pm 0.03$ & $42.6 \pm 0.007$ \\
60 & $51.6 \pm 0.02$ & $55.4 \pm 0.005$ \\
80 & $63 \pm 0.01$ & $79 \pm 0.037$ \\
100 & $70 \pm 0.005$ & $85 \pm 0.01$ \\
\hline
\end{tabular}




\section{CONCLUSION}

In summary, the methanolic extract of J.regia leaves was examined for its anti-inflammatory and antimicrobial properties. The extract was active against Gram-positive bacteria, and fungus, revealing their antimicrobial properties. In addition, the extract produced anti-inflammatory effect. The findings of this study suggest potential use of J.regia leaves extract as antimicrobial and anti-inflammatory agent.

\section{ACKNOWLEDGMENT}

The authors are thankful to the Department of Pharmaceutics, King Saud University for grant support.

\section{Conflict of interest}

The authors have no conflict of interest.

\section{REFERENCES}

1. Firenzuoli, F.; Gori, L. Evid Based Complement Alternat Med., 2007, 4, 37-40.

2. Shojaii, A.; Dabaghian, F. H.; Goushegir, A.; Fard, M. A. Acta Med Iran., 2011, 49, 637-42.

3. Bahmani, M.; Rafieian-Kopaei, M.; Hassanzadazar, H.; Saki, K.; Karamati, S. A.; Delfan, B. Asian Pacific journal of tropical medicine., 2014, 7, S29-S33.

4. Chopra, R.; Nayar, S.; Chopra, I. New Delhi., 1986, 2-79.

5. Chopra, R. N.; Chopra, I., Indigenous drugs of India.: Academic publishers., 1933.

6. Ahmad, I.; Beg, A. Z. Journal of ethnopharmacology., 2001, 74, 113-123.

7. Noumi, E.; Snoussi, M.; Hajlaoui, H.; Valentin, E.; Bakhrouf, A. European Journal of Clinical Microbiology \& Infectious Diseases., 2010, 29, 81.

8. Chaleshtori, R. S.; Chaleshtori, F.S.; Rafieian, M. Turkish Journal of Biology., 2011, 35, 635-639.

9. Kamyab, H.; Hejrati, S.; Khanavi, M.; Malihi,
F.; Mohammadirad, A.; Baeeri, M.; Esmaily, H.; Abdollahi, M. Cent. Eur. J. Biol., 2010, 5, 304-309.

10. Mohammadi, J.; Mirzaie, A.; Azizi, A.; Roozbehi, A.; Delaviz, H. Iran S Med J., 2012, 4, 293-301.

11. Amaral, J.S.; Seabra R.M.; Andrade P. B.; Valentão P.; Pereira J. A.; Ferreres F. Food Chemistry., 2004, 88, 373-379.

12. Institute, C.a. L. S., Performance Standards for Antimicrobial Susceptibility Testing. Seventh Informational Supplement CLSI document M100-S17., Clinical and Laboratory Standards Institute: 940 West Valley Road, Suite 1400, Wayne, Pennsylvania, USA., 2007.

13. Deshpande, R. R.; Kale, A. A.; Ruikar, A. D.; Panvalkar, P. S.; Kulkarni, A. A.; Deshpande, N. R.; Salvekar, J. P. International Journal of Pharmacy and Pharmaceutical Sciences., 2011, 3, 200-201. 